\title{
PENGEMBANGAN E-MODUL FISIKA TEGAS (TEGANGAN, REGANGAN, DAN MODULUS YOUNG) BERBASIS ANDROID DENGAN PENDEKATAN INQUIRY BASED LEARNING PADA MATERI ELASTISITAS UNTUK SISWA SEKOLAH MENENGAH ATAS
}

\author{
Nurani Sulistyawati $^{\text {a) }}$, Esmar Budi $^{\text {b) }}$, Siswoyo $^{\text {c) }}$ \\ Prodi Pendidikan Fisika Fakultas Matematika dan Ilmu Pengetahuan Alam, Universitas Negeri Jakarta, Jalan \\ Rawamangun Muka, Kota Jakarta Timur, DKI Jakarta (13220) \\ Email: ${ }^{\text {a) }}$ sulistyawatinurani@gmail.com, b) $\underline{\text { esmarbudi @unj.ac.id, }{ }^{c} \text { siswoyo@unj.ac.id }}$
}

\begin{abstract}
Abstrak
Penelitian ini bertujuan untuk mengembangkan E-Modul berbasis android yang membahas materi mengenai Elastisitas untuk siswa Sekolah Menengah Atas dengan pendekatan Inquiry Based Learning yang terdiri dari orientasi, merumuskan masalah, merumuskan hipotesis, mengumpulkan data, menguji hipotesis, dan merumuskan kesimpulan. Penelitian ini didasarkan pada kurangnya media untuk mendukung sebuah proses pembelajaran yang dapat meningkatkan minat dan pemahaman siswa melalui belajar mandiri. Penelitian ini menghasilkan aplikasi berupa software berbasis android pada smartphone. Aplikasi ini dapat menampilkan ringkasan materi, video, dan soal-soal yang berkaitan dengan materi elastisitas. Metode penelitian yang digunakan adalah Research and Development (R\&D) dengan model pengembangan yang digunakan yaitu ADDIE (Analyze, Design, Development, Implementation, Evaluation). Hasil validasi uji kelayakan terhadap e-modul oleh ahli materi memperoleh $86 \%$ dan ahli media memperoleh 78\%. Berdasarkan uji kelayakan tersebut dapat dinyatakan bahwa e-modul layak dijadikan sebagai media pembelajaran mandiri siswa.
\end{abstract}

Kata-kata kunci: android, e-modul, elastisitas, fisika kelas XI, inquiry based learning

\begin{abstract}
The aim of this research was to develop Android-based E-Modules which discussed subject about Elasticity for high school student with Inquiry Based Learning approach that consists of orientation, problem formulation, hypotheses formulation, collection the data, testing the hypotheses and conclusion formulation. This research is based on the lack of media to support learning process that can increases students' interest and understanding through independent learning. This research produced an application that is android-based software on the smartphone. This application can display the summaries of subjects, videos, and questions related to elasticity subject. The research methodology used in this research was Research and Development (R\&D) method with ADDIE's development model
\end{abstract}


(Analyze, Design, Development, Implementation, Evaluation). The result of validity test of E-modules by subject experts obtained $86 \%$ and media experts received $78 \%$. Based on the validity test, it can be stated that E-modules are feasible to be used as students' independent learning media.

Keywords: android, e-module, elasticity, inquiry based learning, physics of class XI

\section{PENDAHULUAN}

Berdasarkan Undang-Undang Sistem Pendidikan Nasional (UU Sisdiknas) Nomor 20 Tahun 2003, pendidikan adalah usaha sadar terencana untuk mewujudkan suasana belajar dan proses pembelajaran agar peserta didik secara aktif mengembangkan potensi dirinya untuk memiliki kekuatan spiritual keagamaan, pengendalian diri, kepribadian, kecerdasan, akhlak mulia, serta keterampilan yang diperlukan dirinya, masyarakat bangsa dan negara [1].

Dalam hal ini tentunya peran dari seorang guru sangat dibutuhkan, guru memiliki peran sebagai controller, organizer, dan prompter. Sebagai controller seorang guru harus berlaku sebagai pengontrol semua kegiatan belajar mengajar. Sebagai organizer, seorang guru memiliki tanggung jawab dalam mengantur peserta didiknya dalam melakukan segala kegiatan di dalam kelas. Sebagai prompter, seorang guru harus senantiasa mengarahkan siswanya agar melakukan sesuatu yang berkaitan dengan tanggung jawabnya dalam belajar [2].

Selain itu, kemampuan dan keterampilan dalam suatu pembelajaran tentunya harus bisa diterapkan di dalam kegiatan pembelajaran fisika. Fisika sebagai ilmu dasar memiliki karakteristik yang mencakup bangun ilmu yang terdiri atas fakta, konsep, prinsip, hukum, postulat, dan teori serta metodologi keilmuan [3].

Fakta di lapangan menunjukkan bahwa pelajaran fisika dianggap sebagai salah satu cabang ilmu yang menakutkan, hal ini terjadi karena sikap siswa yang sudah tertutup oleh rasa takut. Rasa takut yang dirasakan siswa membawa akibat siswa enggan mengajukan pertanyaan yang sebenarnya mereka belum paham pada suatu materi [4]. Hal ini tentunya membuat pendidik senantiasa berpikir untuk memilih media pembelajaran yang tepat.

Menurut Gerlach dan Ely (1971) mengemukakan bahwa media pembelajaran merupakan alat-alat grafis, fotografis untuk menangkap, memproses dan menyusun kembali informasi visual atau verbal. Media pembelajaran juga memiliki fungsi yaitu memvisualisasikan seuatu yang tidak dapat dilihat atau sukar dilihat sehingga nampak jelas dan dapat menimbulkan pengertian atau meningkatkan persepsi seseorang [5]. Sehingga media pembelajaran terkini yang melibatkan kecanggihan TIK (Teknologi Informasi dan Komunikasi) merupakan salah satu upaya yang dapat dilakukan untuk mengatasi masalah pembelajaran dengan mengembangkan suatu media pembelajaran yang dapat menunjang minat, kemampuan serta keterampilan siswa.

Perkembangan media pembelajaran dengan tekonologi dapat mendorong terjadinya perpaduan antara teknologi cetak dangan teknologi komputer dalam kegiatan pembelajaran. Sehingga modul dapat ditansformasikan penyajiannya ke dalam bentuk elektronik atau e-modul [6]. E-Modul berbasis android merupakan suatu media pembelajaran yang dapat dilakukan melalui smartphone. E-Modul berisikan peta konsep, uraian materi, pertanyaan, tugas mandiri serta video pembelajaran yang telah disusun berdasarkan kompetensi dan indikator yang harus dicapai dalam suatu pembelajaran. EModul berbasis android dapat dijadikan suatu media pembelajaran yang inovatif serta kreatif sehingga mampu untuk mengembangkan minat, kemampuan serta keterampilan siswa.

Android saat ini merupakan sebuah media teknologi komunikasi serta serta merupakan satu sistem aplikasi yang paling banyak digunakan di dunia serta di gemari oleh masyarakat.Android dapat diartikan sebagai sebuah sistem operasi yang digunakan untuk perangkat mobile yang menyediakan platform terbuka bagi para pengembang untuk dapat menciptakan aplikasi yang telah dibuat.

Sementara itu, model pembelajaran yang cocok untuk mendukung proses pembelajaran menggunakan Inquiry Based Learning yang merupakan suatu pendekatan yang digunakan dan mengacu pada suatu cara untuk mempertanyakan, mencari pengetahuan (informasi), atau mempelajari suatu gejala [7]. Kelebihan dari Inquiry Based Learning merupakan strategi 
pembelajaran yang menekankan kepada pengembangan aspek kognitif, afektif dan psikomotor serta dapat melayani kebutuhan siswa yang memiliki kemampuan diatas rata-rata. Adapun kekurangannya yaitu memerlukan kecerdasan siswa yang tinggi dan memerlukan perubahan kebiasaan cara belajar siswa yang menerima informasi dari guru apa adanya [8].

Hasil analisis kebutuhan yang menyatakan bahwa 63,33\% siswa mengalami kesulitan dalam mempelajari elastisitas dengan $20 \%$ siswa tidak dapat memahami isi materi elastisitas dengan baik, dan $36.66 \%$ siswa tidak bisa menyelesaikan soal yang beragam mengenai materi elastisitas, hal tersebut tentunya mempengaruhi hasil belajar siswa terkait materi elastisitas ini terbilang rendah. Rendahnya hasil belajar ini dapat disebabkan oleh banyak faktor lain, diantaranya media pembelajaran yang kurang mendukung dalam proses pembelajaran. Oleh karena itu, pengembangan e-modul berbasis android ini memiliki tujuan agar proses pembelajaran menjadi lebih efisien dengan cara menggali siswa membentuk pengetahuan yang dimilikinya dengan menggunakan media pembelajaran tersebut serta dapat membangun pola pikir yang kreatif dan luas.

Berdasarkan uraian dan pemabahasan tersebut E-Modul berbasis android hadir untuk dapat dijadikan alternatif dalam meningkatkan minat dan pemahaman siswa melalui belajar mandiri untuk pembelajaran elastisitas dengan pendekatan Inquiry Based Learning untuk siswa Sekolah Menengah Atas.

\section{METODOLOGI}

Berdasarkan Undang-Undang Sistem Pendidikan Nasional (UU Sisdiknas) Nomor 20 Tahun 2003, pendidikan adalah usaha sadar terencana untuk mewujudkan suasana belajar dan proses pembelajaran agar peserta didik secara aktif mengembangkan potensi dirinya untuk memiliki kekuatan spiritual keagamaan, pengendalian diri, kepribadian, kecerdasan, akhlak mulia, serta keterampilan yang diperlukan dirinya, masyarakat bangsa dan negara [1].

Dalam hal ini tentunya peran dari seorang guru sangat dibutuhkan, guru memiliki peran sebagai controller, organizer, dan prompter. Sebagai controller seorang guru harus berlaku sebagai pengontrol semua kegiatan belajar mengajar. Sebagai organizer, seorang guru memiliki tanggung jawab dalam mengantur peserta didiknya dalam melakukan segala kegiatan di dalam kelas. Sebagai prompter, seorang guru harus senantiasa mengarahkan siswanya agar melakukan sesuatu yang berkaitan dengan tanggung jawabnya dalam belajar [2].

Selain itu, kemampuan dan keterampilan dalam suatu pembelajaran tentunya harus bisa diterapkan di dalam kegiatan pembelajaran fisika. Fisika sebagai ilmu dasar memiliki karakteristik yang mencakup bangun ilmu yang terdiri atas fakta, konsep, prinsip, hukum, postulat, dan teori serta metodologi keilmuan [3].

Fakta di lapangan menunjukkan bahwa pelajaran fisika dianggap sebagai salah satu cabang ilmu yang menakutkan, hal ini terjadi karena sikap siswa yang sudah tertutup oleh rasa takut. Rasa takut yang dirasakan siswa membawa akibat siswa enggan mengajukan pertanyaan yang sebenarnya mereka belum paham pada suatu materi [4]. Hal ini tentunya membuat pendidik senantiasa berpikir untuk memilih media pembelajaran yang tepat.

Menurut Gerlach dan Ely (1971) mengemukakan bahwa media pembelajaran merupakan alat-alat grafis, fotografis untuk menangkap, memproses dan menyusun kembali informasi visual atau verbal. Media pembelajaran juga memiliki fungsi yaitu memvisualisasikan seuatu yang tidak dapat dilihat atau sukar dilihat sehingga nampak jelas dan dapat menimbulkan pengertian atau meningkatkan persepsi seseorang [5]. Sehingga media pembelajaran terkini yang melibatkan kecanggihan TIK (Teknologi Informasi dan Komunikasi) merupakan salah satu upaya yang dapat dilakukan untuk mengatasi masalah pembelajaran dengan mengembangkan suatu media pembelajaran yang dapat menunjang minat, kemampuan serta keterampilan siswa.

Perkembangan media pembelajaran dengan tekonologi dapat mendorong terjadinya perpaduan antara teknologi cetak dangan teknologi komputer dalam kegiatan pembelajaran. Sehingga modul dapat ditansformasikan penyajiannya ke dalam bentuk elektronik atau e-modul [6]. E-Modul berbasis 
android merupakan suatu media pembelajaran yang dapat dilakukan melalui smartphone. E-Modul berisikan peta konsep, uraian materi, pertanyaan, tugas mandiri serta video pembelajaran yang telah disusun berdasarkan kompetensi dan indikator yang harus dicapai dalam suatu pembelajaran. EModul berbasis android dapat dijadikan suatu media pembelajaran yang inovatif serta kreatif sehingga mampu untuk mengembangkan minat, kemampuan serta keterampilan siswa.

Android saat ini merupakan sebuah media teknologi komunikasi serta serta merupakan satu sistem aplikasi yang paling banyak digunakan di dunia serta di gemari oleh masyarakat.Android dapat diartikan sebagai sebuah sistem operasi yang digunakan untuk perangkat mobile yang menyediakan platform terbuka bagi para pengembang untuk dapat menciptakan aplikasi yang telah dibuat.

Sementara itu, model pembelajaran yang cocok untuk mendukung proses pembelajaran menggunakan Inquiry Based Learning yang merupakan suatu pendekatan yang digunakan dan mengacu pada suatu cara untuk mempertanyakan, mencari pengetahuan (informasi), atau mempelajari suatu gejala [7]. Kelebihan dari Inquiry Based Learning merupakan strategi pembelajaran yang menekankan kepada pengembangan aspek kognitif, afektif dan psikomotor serta dapat melayani kebutuhan siswa yang memiliki kemampuan diatas rata-rata. Adapun kekurangannya yaitu memerlukan kecerdasan siswa yang tinggi dan memerlukan perubahan kebiasaan cara belajar siswa yang menerima informasi dari guru apa adanya [8].

Hasil analisis kebutuhan yang menyatakan bahwa 63,33\% siswa mengalami kesulitan dalam mempelajari elastisitas dengan $20 \%$ siswa tidak dapat memahami isi materi elastisitas dengan baik, dan $36.66 \%$ siswa tidak bisa menyelesaikan soal yang beragam mengenai materi elastisitas, hal tersebut tentunya mempengaruhi hasil belajar siswa terkait materi elastisitas ini terbilang rendah. Rendahnya hasil belajar ini dapat disebabkan oleh banyak faktor lain, diantaranya media pembelajaran yang kurang mendukung dalam proses pembelajaran. Oleh karena itu, pengembangan e-modul berbasis android ini memiliki tujuan agar proses pembelajaran menjadi lebih efisien dengan cara menggali siswa membentuk pengetahuan yang dimilikinya dengan menggunakan media pembelajaran tersebut serta dapat membangun pola pikir yang kreatif dan luas.

Berdasarkan uraian dan pemabahasan tersebut E-Modul berbasis android hadir untuk dapat dijadikan alternatif dalam meningkatkan minat dan pemahaman siswa melalui belajar mandiri untuk pembelajaran elastisitas dengan pendekatan Inquiry Based Learning untuk siswa Sekolah Menengah Atas.

\section{HASIL DAN PEMBAHASAN}

Produk dari hasil pengembangan ini berupa E-Modul Fisika TEGAS (Tegangan, Regangan, dan Modulus Young) berbasis android dengan pendekatan Inquiry Based Learning pada materi elastisitas untuk siswa sekolah menengah atas sebagai media pembelajaran yang dapat digunakan menggunakan smartphone.

E-Modul yang dikembangkan terdiri dari beberapa komponen yaitu cover, menu homepage, daftar isi, capaian kompetensi, menu pembelajaran yang terdiri dari pre test, peta konsep, materi elastisitas yang terdiri dari teks materi, gambar, video, contoh soal dan pembahasan, serta latihan soal, dan post test serta terdapat menu about. Dalam penyajiannya, e-modul fisika berbasis android pada materi elastisitas ini di desain sesuai dengan tahapan model pembelajaran Inquiry Based Learning yang terdiri dari beberapa tahapan, yaitu tahap orientasi, merumuskan massalah, hipotesis, tahap pengumpulan data, menguji hipotesis, dan menarik kesimpulan.

Dibawah ini adalah hasil desain tampilan E-Modul Fisika TEGAS (Tegangan, Regangan, dan Modulus Young) berbasis android dengan pendekatan Inquiry Based Learning pada materi elastisitas untuk siswa sekolah menengah atas. 

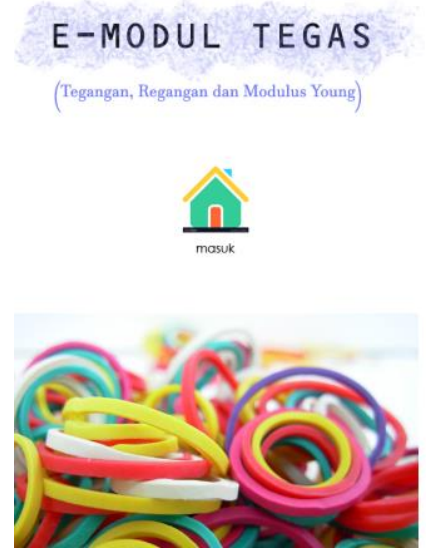

GAMBAR 1. Cover

\section{Pembelajaran}

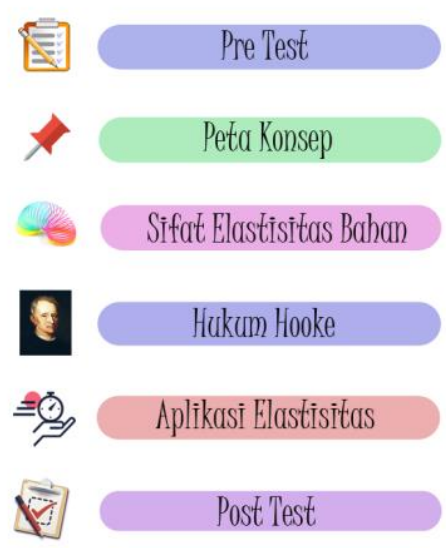

GAMBAR 4. Menu Pembelajaran

Peta Konsep

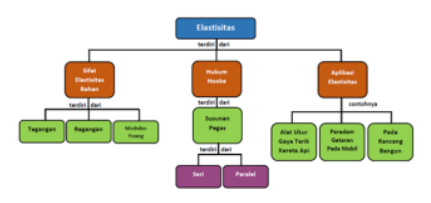

กิ

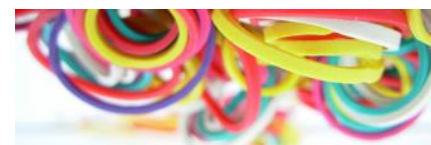

\section{Selamat Datang}

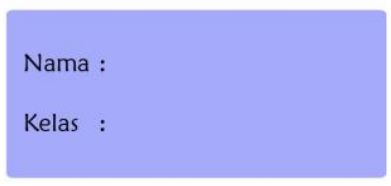

Jangan Lupa mengisi nama dan kelas
sebagai tanda absensi kamu
Daftar Isi

Capaian Kompetensi

Pembelajaran

About
GAMBAR 2. Halaman Awal

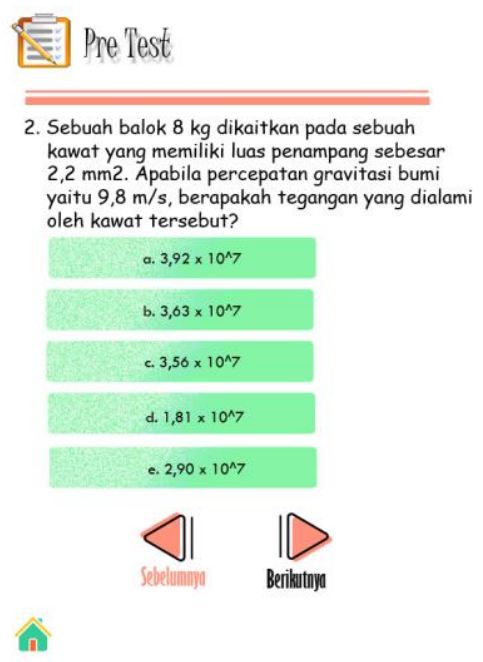

GAMBAR 5. Soal Pre Test

\section{Jegangan}

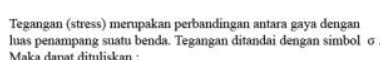

luas penampang suatu be
Maka dapat dituliskan :

$\sigma=\mathrm{F} / \mathrm{A}$

Keterangan:
F: Besar gaya tekan (N)
A: Luas penampang (m2)

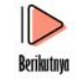

กิ

GAMBAR 8. Materi Elastisitas
GAMBAR 3. Daftar Isi

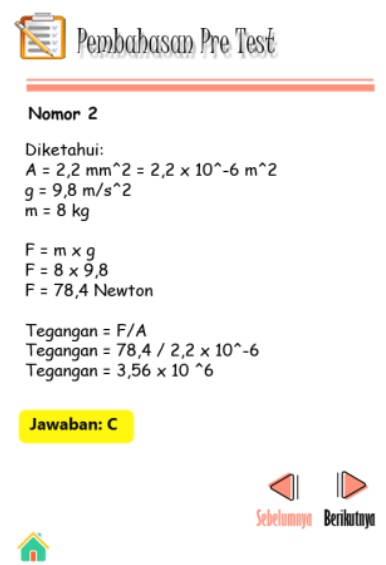

GAMBAR 6. Pembahasan Pre Test

Sifat Elastisitas Bahon

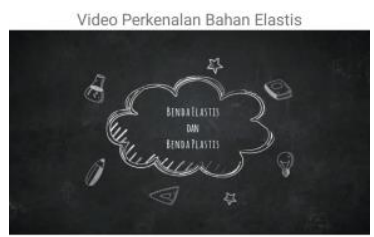

10

GAMBAR 7. Peta Konsep 


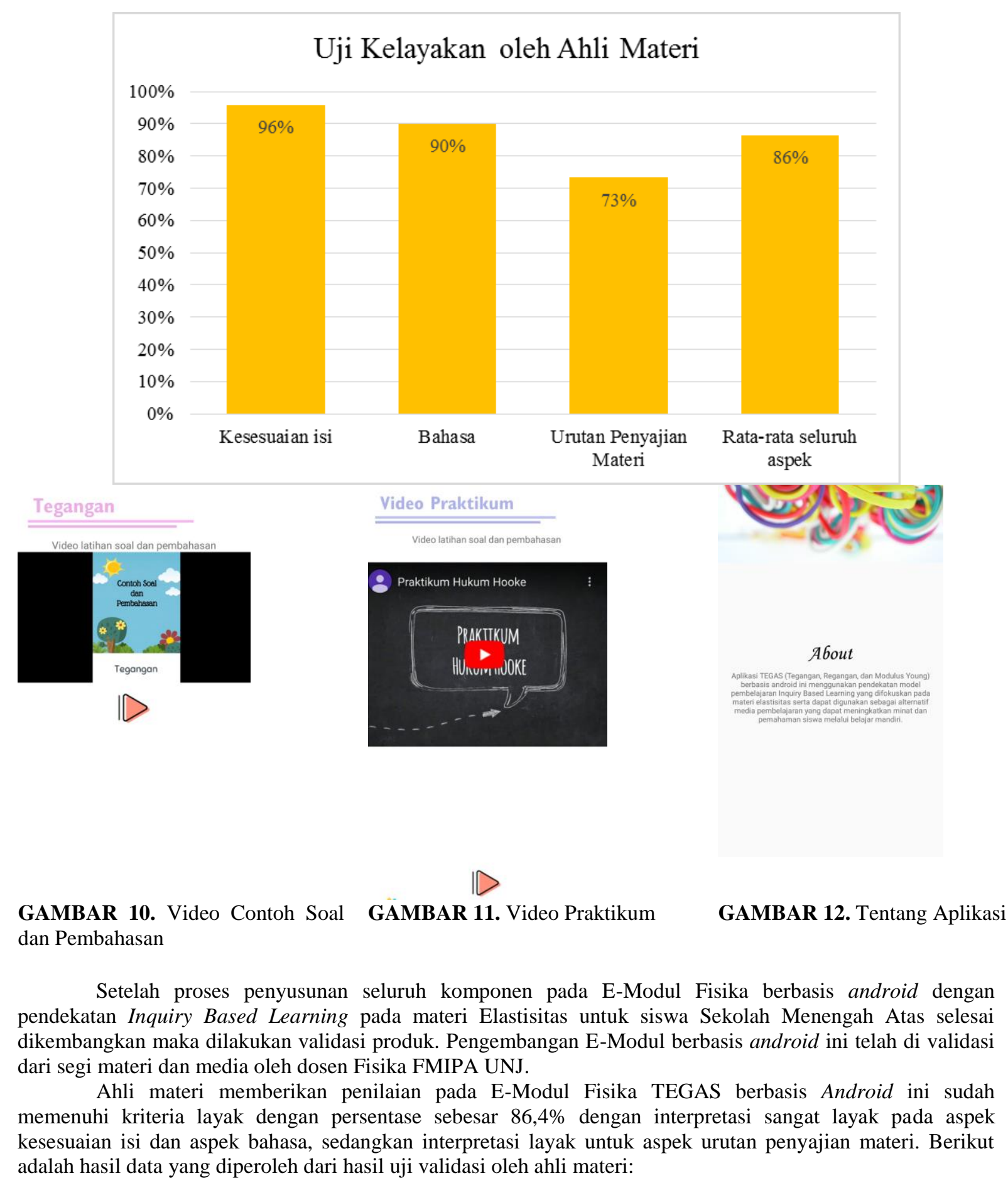




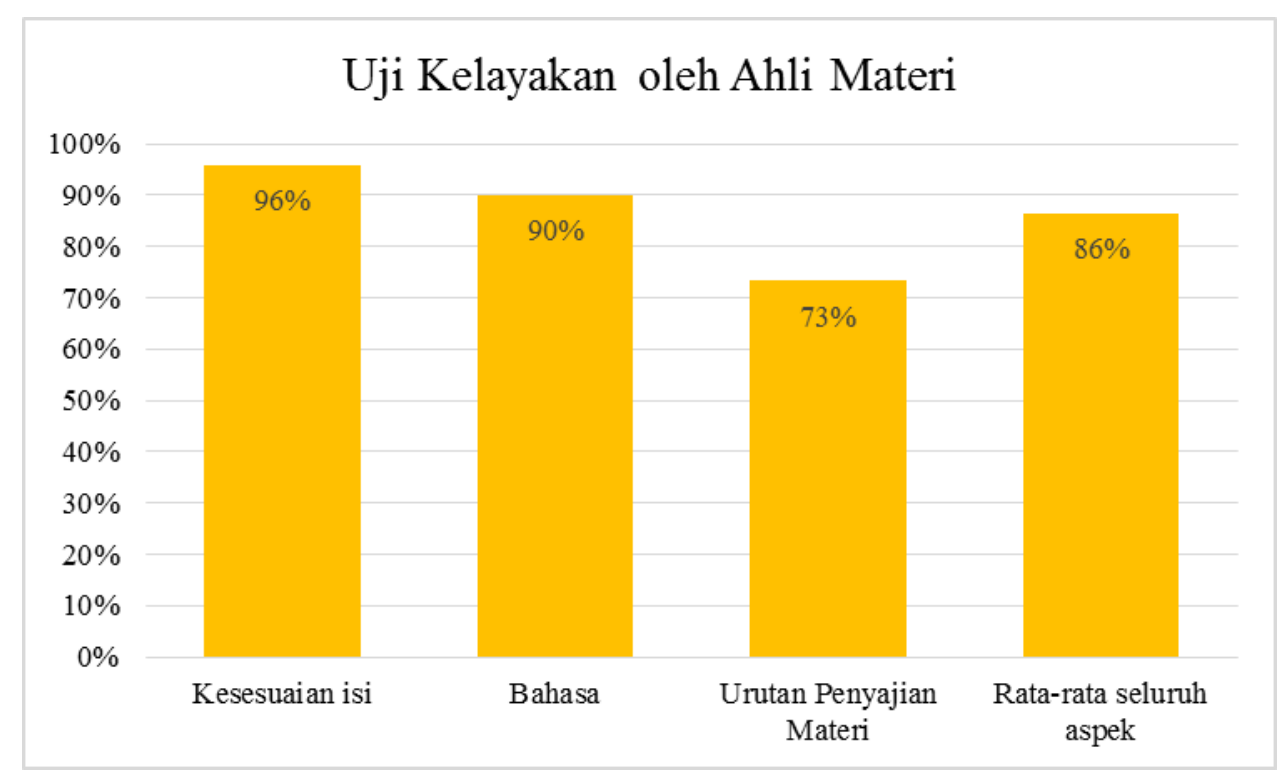

GAMBAR 13. Hasil Uji Kelayakan E-Modul Fisika TEGAS oleh Ahli Materi

Hasil validasi kelayakan E-Modul Fisika TEGAS berbasis android oleh ahli media menunjukkan rata-rata persentase sebesar $78 \%$ dengan interpretasi layak pada aspek visualisasi media, aspek bahasa dan aspek rekayasa perangkat lunak. Berikut adalah hasil data yang diperoleh dari hasil uji validasi oleh ahli media:

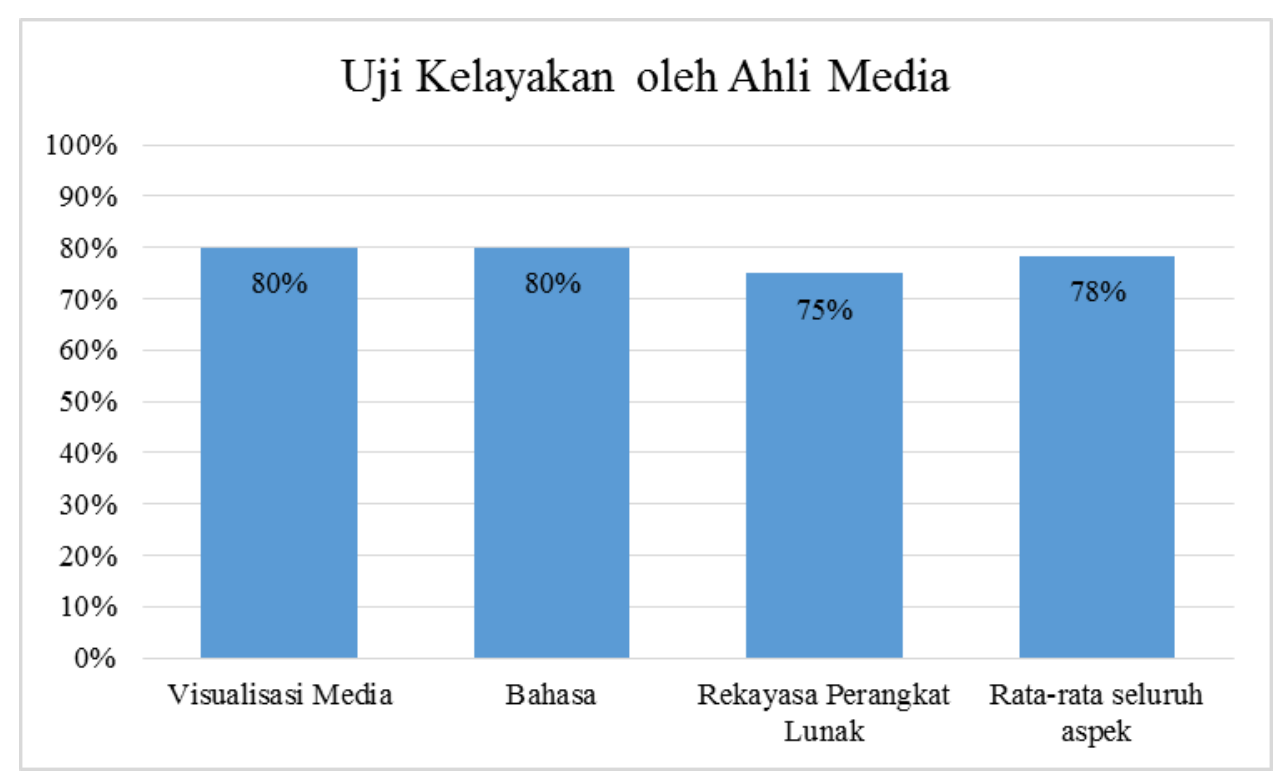

GAMBAR 14. Hasil Uji Kelayakan E-Modul Fisika TEGAS oleh Ahli Media

\section{SIMPULAN}

Berdasarkan hasil penelitian, dapat disimpulkan bahwa E-Modul Fisika TEGAS dengan pendekatan Inquiry Based Learning berbasis android pada materi elastisitas untuk siswa Sekolah Menengah Atas yang dikembangkan memperoleh persentase sebesar $86 \%$ pada ahli materi, dan $78 \%$ pada ahli media. Dengan berdasarkan skala kelayakan menyatakan bahwa E-Modul Fisika TEGAS dengan pendekatan Inquiry Based Learning berbasis android pada materi elastisitas untuk siswa 
Sekolah Menengah Atas yang dikembangkan layak menjadi media pembelajaran untuk meningkatkan minat dan pemahaman siswa melalui belajar mandiri.

\section{REFERENSI}

[1] Depdiknas, Undang-undang RI No.20 Tahun 2003 tentang Sistem Pendidikan Nasional, 2003.

[2] T. P. I. P. FIP-UPI, "Ilmu dan Aplikasi Pendidikan," Bandung, Grasindo, 2007, p. 91.

[3] N. S. Pratama and E. Istiyono, "Studi Pelaksanaan Pembelajaran Fisika Berbasis Higher Order Thinking (HOTS) Pada Kelas X di SMA Negeri Kota Yogyakarta," Prosiding Seminar Nasional Fisika dan Pendidikan Fisika (SNFPF) Ke-6, Vol. 6 No.1, p. 104, 2015.

[4] N. L. Luntungan, S. and D. Wahyuningsih, "Upaya Peningkatan Kreativitas Siswa Melalui Implementasi Blended Learning Pada Pembelajaran Fisika kelas VIII A SMP 1 Mantinga," Jurnal Pendidikan Fisika. Vol. 1(1), p. 65, 2013.

[5] M. R. Sumiharsono and H. Hasanah, "Media Pembelajaran," Jember, Pustaka Abadi, 2018, pp. 9-10.

[6] A. C. Dewi, "Pengembangan Modul Elektronik Pada Mata Pelajaran Produktif Kompetensi Etimologi Multimedia Kelas X Sekolah Menengah Kejuruan," Jurnal Pendidikan Teknik Informasi , p. 3, 2016.

[7] N. Nurjanah, "Penerapan Model Pembelajaran Inquiry Based Learning Dalam Meningkatkan Kemampuan Berhitung Dan Operasi Bilangan Anak Usia Dini," Jurnal Program Studi Pendidikan Guru PAUD STKIP Siliwangi Bandung 3 (2), p. 107, 2017.

[8] A. Shoimin, "68 Model Pembelajaran Inovatif dalam Kurikulum 2013," Yogyakarta, Ar-Ruzz Media, 2014, pp. 86-87.

[9] U. Usmeldi, "Pengembangan Modul Pembelajaran Fisika Berbasis Riset dengan Pendekatan Scientific untuk Meningkatkan Literasi Sains Peserta Didik”, jpppf, vol. 2, no. 1, pp. 1 - 8, Jun. 2016.

[10] N. Nurhayati and B. Boisandi, "Penggunaan Modul Berbasis Konstruktivis pada Mata Kuliah Fisika Kuantum untuk Meningkatkan Penguasaan Konsep ditinjau dari Kemampuan Matematik Mahasiswa", ipppf, vol. 1, no. 2, pp. 33 - 38, Dec. 2015.

[11] F. Bakri, R. Rasyid, and R. D. A. Mulyaningsih, "Pengembangan Modul Fisika Berbasis Visual untuk Sekolah Menengah Atas (SMA)", jpppf, vol. 1, no. 2, pp. 67 - 74, Dec. 2015.

[12] U. R. Fitri, D. Desnita, and E. Handoko, "Pengembangan Modul Berbasis Discovery-Inquiry untuk Fisika SMA Kelas XII Semester 2”, jpppf, vol. 1, no. 1, pp. 47 - 54, Jun. 2015.

[13] S. Trisnaa and A. Rahmi, "Validitas Modul Pembelajaran Berbasis Guided Inquiry pada Materi Fluida di STKIP PGRI Sumatera Barat", jpppf, vol. 2, no. 1, pp. 9 - 14, Jun. 2016.

[14] S. Syahrowardi and A. H. Permana, "Desain Handout Multimedia Menggunakan 3D Pageflip Professional untuk Media Pembelajaran pada Sistem Android", jpppf, vol. 2, no. 1, pp. 89 - 96, Jun. 2016.

[15] F. Bakri, B. Z. Siahaan, and A. H. Permana, "Rancangan Website Pembelajaran Terintegrasi dengan Modul Digital Fisika Menggunakan 3D PageFlip Professional", jpppf, vol. 2, no. 2, pp. 113 - 118, Dec. 2016

[16] Ambarwulan, D., \& Muliyati, D. (2016). The Design of Augmented Reality Application as Learning Media Marker-Based for Android Smartphone. Jurnal Penelitian \& Pengembangan Pendidikan Fisika, 2(1), 73 80.

[17] Budi, A., \& Muliyati, D. (2018, May). Discovering and understanding the vector field using simulation in android app. In Journal of Physics: Conference Series (Vol. 1013, No. 1, p. 012062). IOP Publishing.

[18] Muliyati, D., Bakri, F., \& Ambarwulan, D. (2018). Aplikasi Android Modul Digital Fisika Berbasis Discovery Learning. WaPFi (Wahana Pendidikan Fisika), 3(1), 74-79. 